\title{
Economic and Social Status in Household Decision Making: Evidence from Extended Family Mobility
}

\author{
Chang, Chin-Oh* Shu-Mei Chen** Tsur Somerville***
}

June 2002

* Professor, Department of Land Economics, National Chengchi University, Taipei, TAIWAN.

Tel: +886-2-29387478 Fax: 886-2-29390251 E-mail: jachang@nccu.edu.tw

** Department of Real Estate Management, Kun Shan University of Technology, Tainan, TAIWAN.

E-mail: $\underline{\text { mayc2110@ms24.hinet.net }}$

${ }^{* * *}$ Faculty of Commerce, University of British Columbia, 2053 Main Mall, Vancouver, BC, V6T 1Z2, CANADA. Tel: (604) 822-8343, Fax: (604) 822-8477. Email: tsur.somerville@commerce.ubc.ca

We would like to thank John McDonald and two unnamed referees for their instructive and helpful and instructive comments. 


\begin{abstract}
Models of the allocation of household resources use as a decision rule either the maximization of a household utility function (Becker, 1984) or the solution to a Nash-bargaining game (McElroy and Horney, 1981). To date the mobility literature has exclusively utilized the former approach to analyze the household's decision to change location. This is despite the strong empirical evidence that allocations in other areas are more consistent with the bargaining model. In this paper we use micro-data from Taipei, Taiwan to determine which approach is most appropriate for studying housing mobility decisions. We compare the mobility decisions of nuclear and different types of extended family households to test whether the social and economic roles of different generations affect the household decision process, as is consistent with the bargaining approach. In doing so, we analyze household mobility with a richer description of household structure than is found in the current literature, which implicitly treats households as either a nuclear family or some smaller unit. Our results support the bargaining model of household decision making. Conditional probabilities differ between nuclear and extended families, when a member of the eldest generation in an extended household is the household head, and when a member of the eldest generation contributes to household earnings.
\end{abstract}




\section{Introduction}

The decision to move involves changes in commute times, neighborhood amenities, and social networks. These changes cannot be expected to have equal effects on the utility of each member of a household. For multi-member households, a model of mobility must be embedded in a model of household decision making. Two general alternative frameworks exist for modeling this decision process. The common preference (Becker, 1964) and Nash-bargaining (McElroy and Horney, 1981) approaches differ in the role they give to individual household member preferences in intra-family resource allocation. This difference has important implications for the mobility decision, primarily in the treatment of the opportunity costs of mobility. In this paper, we look at the relationship between household social and economic structure and mobility decisions to determine which approach is most appropriate for modeling mobility. In doing so, we make a second contribution by extending mobility analysis beyond the characterization as a nuclear family or smaller unit to include extended families.

Housing demand studies use the household as their basis of analysis. The structure of most research implicitly assumes that households are either a nuclear family or some smaller unit. Differences in household structure result because the household head is female, adults are not married, household size, or in the number of children. Yet, in many parts of the world more traditional family structures, where households include more than two generations or two or more related families, are much more common. With rising immigration this is increasingly important in first world countries as well immigrants are more likely to live in extended family arrangements. In the United States in 1990, households whose head was born outside of the US made up $4.2 \%$ of all households, but $7.6 \%$ of all extended households, a rate of 
extended family formation that is 81 percent higher than for the total population. ${ }^{1}$ For Canada, the extended family formation rate for immigrants is $169 \%$ higher. For some cities this is particularly relevant as the households head is an immigrant in over $20 \%$ of households in Los Angeles and Miami.

A core issue in this study is the effect of non-financial transactions costs on household mobility decisions. When a move occurs, individuals in the family are likely to experience a disruption in their links with their community of origination. We use this cost and the consistent result that mobility falls with age to see how mobility behavior varies by family type, between nuclear and extended families, within different types of extended families, differentiating by whether the household head is in the $1^{\text {st }}$ generation (eldest / grandparent) or $2^{\text {nd }}$ generation (parent), and whether the head is the primary earner or not. Our prior is that both family type and the choice of head reflect the family's social structure. The number, make-up, and importance of income earners reflect its economic structure. If mobility behavior differs by choice of head, number of generations, or identify of income earners, we find support for the bargaining framework of household allocation decisions over common preferences. For the latter course, what we are interested in is if conditional on both total income and number of earners, if the identify of the earners matters. Properly specified, the different outcomes will reflect either social or economic factors that strengthen the bargaining position of a given household member relative to others in determining household decisions such as moving.

We find important differences in mobility decisions depending on a household's social and economic hierarchy. However, economic contribution matters more than social status. Conditional mobility rates are lower for extended families than for nuclear families. Among extended families, the same are lower if the head of household is in the eldest generation. They are also lower if a member of the eldest 
generation contributes to household earnings. Finally, they are lower still if the elder generation household head is the primary earner in the household. Of these, the largest effect on the conditional marginal mobility probability is when the eldest generation household head earns income. This result is inconsistent with Becker's common preferences characterization of the household resource allocation and decision making process, but consistent with the bargaining methodology.

The paper is structured as follows. In Section 2 we present the theoretical and empirical framework for modeling the mobility decisions of households. We present the data in Section 3. The empirical results are presented in Section 4. We conclude the paper in Section 5 with a discussion of future research.

\section{Theoretical and Empirical Framework}

The traditional or neo-classical model of household decision making stems from (Becker's, 1964) application of the model of individual consumer demand to families. In this framework, all members of the household exhibit common preferences by jointly maximizing a single household welfare function. This yields a model that treats the household as equivalent to a single individual, but where there are pooled resources. Outside of the labor-leisure tradeoff, which family member provides the resources is immaterial as allocations reflect the marginal rates of substitution between elements of the joint welfare function. If for all $J$ household members there is a vector $X$ of $i$ goods with price vector $P$ and each member has income $y$, then the demand function for each good depends on prices and total income:

$$
X_{i}=\sum_{j}^{J} X_{i j}=f\left(P, \sum_{j}^{J} y_{j}\right)
$$

Only total household income, the sum of the $y_{j}$ terms, matters, not its distribution. As 
result we would expect consumption patterns to be invariant to who obtains the income.

This approach has come under attack by researchers such as (Manser and Brown, 1980) and (McElroy and Horney, 1981 and 1990). ${ }^{2}$ Among others, they propose an alternative characterization of the household as allocating resources internally following a bargaining framework. Household members have individual utility functions that contain both private and joint consumption goods. Instead of pooling, household members have an incentive to allocate resources in the direction of goods that they particularly care about. For instance, (McElroy and Horney, 1981) use a co-operative Nash-bargaining game among members to allocate resources. The outcome depends on a household member's prospective utility outside the household. Their bargaining position is strengthened the greater the income or wealth they can control. As these increase, a member is better able to obtain an allocation that more closely matches their personal preferences because of the stronger and more credible threat to leave the household and achieve a purely private utility outcome. In comparison to (1), demand now separately reflects the individual incomes:

$$
X_{i}=\sum_{j}^{J} X_{i j}=f\left(P, y_{1}, \ldots, y_{J}\right)
$$

Individual income is no longer substitutable as was the case in (1) as the distribution of total y among the individual $y_{j}$ 's matters.

There is a substantive empirical literature that demonstrates that households behave in a manner more consistent with the second framework of associated individuals rather than the manner described in the "common preference" neo-classical model. (Thomas, 1990) looks at the effect on family health of unearned income in the hands of mothers and fathers and finds that unearned income in the hands of a mother yields a bigger effect on family health and dramatically higher child survival probabilities. In a paper of interest to our topic, (Hayashi, 1995) looks at the food 
expenditures of Japanese extended families and finds that as the income of the senior generation rises, household expenditures on food more closely mirror the population preferences of the elderly. Both of these, and the other papers in this literature such as (Cai, 1989), (Schultz, 1990), and (Browning et al., 1994), find that allocations are affected by the resources brought to the household by an individual member. This result is inconsistent with common preferences.

In this paper we extend this analysis to the mobility decisions of households. The central question is whether mobility decisions are affected by social status and contribution to household resources, as predicted by the bargaining model. Our hypothesis is that the greater the role of the elderly first generation, the lower the mobility probability. We describe role in terms of social status, whether the household head is in the first generation, and by economic contribution, whether an elderly head contributes income or is the primary economic resource. Underlying this hypothesis is the strong assumption that older household members are less likely to move. This is consistent with the literature, which includes (Clark, 1992), (Clark and Drever, 2000), (Kan, 1999), (Chen and Chang, 2000), and (Kan, 2000) among many others, that finds mobility falling in household head age.

Over time, individuals living in a place develop a complex network of friends, social organizations, and casual economic relationships. If these social connections attenuate with distance, then the increased difficulty of maintaining these relationships is an opportunity cost to mobility, which we refer to as the social cost of mobility. ${ }^{3}$ We expect this social cost will increase with age. For example, the dislocation costs to an elder who has lived in an area for many years should be much greater than it is for a younger member.

There is an extensive literature on mobility, but this paper is one of the first to address the issue for extended families. To date mobility research has examined 
mobility and a variety of different factors and with more sophisticated joint and simultaneous decision processes. See (Quigley and Weinberg, 1977) for a review of the early literature. Among a large volume of more recent work are treatments of mobility and income by (McLeod and Ellis, 1983) and (Seek, 1983), the effect of life-cycle events on mobility (Clark and Onaka, 1983), and (Kiel, 1994) on house price movements and mobility. The analysis of mobility as part of a joint, simultaneous decision includes the relationship between tenure and mobility (Boehm, 1981), (Ioannides, 1987), (Zorn, 1988), (Ioannides and Kan, 1996), and (Kan, 1999) and between renovation and mobility (Montgomery, 1992). One paper that does look at more complex family structures and housing demand and mobility is (Chang and Chen, 1999). They investigate the role of life-cycle stages on housing demand and mobility using a typology of 9 different household types.

In the mobility literature, changes in a household's life cycle stage or income affect the decision to move. In all cases, the decision is modeled in a common preferences utility framework, comparing household utility at the household's current location relative to that at alternative locations. In the absence of the ability to improve the current location through renovations and additions, and ignoring tenure choice, the mobility decision is a binary- response choice. ${ }^{4}$ We observe an ex-post decision to move or not to move. Under the common preferences model, this would be the case of moving when the household welfare function has utility of moving $\left(U_{i 1}\right)$ greater than that of not moving $\left(U_{i 0}\right)$. In this frame work, for household $i$, we can characterize the expression as the function of a set of household and location/structure characteristics $X$ and $Z$ :

$$
\begin{aligned}
& \mathrm{U}_{\mathrm{i} 1}=\alpha_{1}+\gamma_{1} \mathrm{X}_{\mathrm{i}}+\beta \mathrm{Z}_{1}+\varepsilon_{\mathrm{i} 1} \\
& \mathrm{U}_{\mathrm{i} 0}=\alpha_{0}+\gamma_{0} \mathrm{X}_{\mathrm{i}}+\beta \mathrm{Z}_{0}+\varepsilon_{\mathrm{i} 0}
\end{aligned}
$$

The probability model of choosing moving is: 


$$
\mathrm{P}\left(\mathrm{U}_{\mathrm{i} 1}>\mathrm{U}_{\mathrm{i} 0}\right)=\mathrm{P}\left(\varepsilon_{\mathrm{i} 1}-\varepsilon_{\mathrm{i} 0}>\alpha_{0}-\alpha_{1}+\left(\gamma_{0}-\gamma_{1}\right) \mathrm{X}_{\mathrm{i}}+\beta\left(\mathrm{Z}_{0}-\mathrm{Z}_{1}\right)\right.
$$

Between the two locations, the household does not change. If we assume that local public goods and amenities are the same at all locations in Taipei City, then the move decision is independent of location characteristics $Z_{j}$, depending only on household

characteristics $X_{i \cdot{ }^{5}}$ Formally, we will assume that any elements of the excluded $Z$ and $Z$ that are not orthogonal to $X$ are captured in ex-post location fixed effects.

Under the Nash-bargaining approach, we cannot present the mobility decision as a function of a household utility function. Instead, the decision is a function of the bargaining outcome, which depends on the relative utility functions of individual household members inside and outside the family for their respective incomes and endowments. Without estimating these inside and outside the family utility functions, structural estimation of the bargaining model is difficult. Researchers have tended to test this approach by identifying consistent outcomes. For instance, (Hayahsi, 1995) looks at Engel curves and shares rather than levels of household consumption in various age-correlated categories.

\section{Data}

The data are taken from the 1990 Census of Population and Housing for Taipei, Taiwan. To avoid tenure choice issues, we limit the sample to local, civilian, owner-occupier households, yielding a population of 240,589 households. We use Taipei data for two reasons. First, as noted above, relative to the US, extended family households are much more likely to be headed by a member of the elder generation, and we are particularly interested in the effects of household structure. Second, over $80 \%$ of the housing stock in the greater Taipei metropolitan area is multi-family, which allows us to exclude single-family residences. ${ }^{6}$ Additions to multi-family dwelling are 
difficult, costly, and typically illegal so to satisfy a demand for increased housing services, households must move, which allows us to ignore the joint renovation/mobility decision (Montgomery, 1992).

The combination between social structure and economic roles generates four types of extended families based on two divisions. The first is between $1^{\text {st }}$ and $2^{\text {nd }}$ generation households, and the second is whether the head is the primary earner. The individual reported as the household head is same person who is registered as such on the legal documents on file with the local government office so that the concept of headship is recognized by the respondents. In Table 1 we provide the basic counts and frequencies for these categories for Taipei in 1990. Most households are nuclear families. ${ }^{7}$ The univariate values for these families are similar to $2^{\text {nd }}$ generation extended households. Both have an unconditional mobility rate of approximately 31.5 percent, for moves within the last five years. Surprisingly, the head is more likely to be the main provider in the $2^{\text {nd }}$ generation extended families than in the nuclear families. Among extended families, the household head was in the $1^{\text {st }}$ generation in $57 \%$ of extended families. ${ }^{8}$ In contrast, in the US in 1990 only $25 \%$ of extended families were headed by someone of the oldest generation suggesting that more North American extended families occur when an elderly parent moves in with their children rather than a traditional family structure. Independent of family hierarchy, we expect earnings to affect the weights assigned to the preferences of individuals in the household in calculating the aggregate household dislocation costs. To reflect an individual's economic importance to the household, our second division separates households depending on whether or not the head is the primary earner. Among $1^{\text {st }}$ generation households, the head is the primary earner in only $26 \%$ of cases. For $2^{\text {nd }}$ generation heads this rises to $84 \%$, and is $78 \%$ for nuclear families.

The univariate statistics on whether a household moved in the last five years 


\section{Table 1}

\begin{tabular}{l|c|cc|cc} 
& $\begin{array}{c}\text { Total } \\
\text { Sample }\end{array}$ & $\begin{array}{c}\text { Nuclear } \\
\text { family }\end{array}$ & $\begin{array}{c}\text { All } \\
\text { Extended } \\
\text { Families }\end{array}$ & $\begin{array}{c}\mathbf{2}^{\text {sd }} \\
\mathbf{1}^{\text {st }} \text { Generation } \\
\text { Extended } \\
\text { Families }\end{array}$ & $\begin{array}{c}\text { Generation } \\
\text { Extended } \\
\text { Families }\end{array}$ \\
\hline No. of Households & 175,421 & 155,757 & 19,664 & 11,527 & 8,137 \\
\% of Total & 100.0 & 88.8 & 11.2 & 6.6 & 4.6 \\
\% Moved in Last 5 Years & 30.6 & 31.4 & 23.8 & 18.2 & 31.6 \\
\% With Head as Main Provider & 72.1 & 74.9 & 49.4 & 24.6 & 84.2
\end{tabular}


clearly shows aggregate differences among household types. Nuclear families are more mobile than extended families, 31.9 to $24.2 \%$ of these families that have moved within the last 5 years. However, when we breakdown extended families by type, it is quite evident, it is those families where the elders are the household head, the more traditional family structure that we label " 1 st generation", that drive the lower mobility rate. Only $18.5 \%$ of these $1^{\text {st }}$ generation extended families have moved within the last 5 years, compared with a surprising $31.6 \%$ of $2^{\text {nd }}$ generation extended family households, which is effectively identical to that of nuclear families.

In Table 2 we provide mean variable values for all families and broken down by family type. Tests for difference of means reject equality in nearly all cases, which is not surprising given the sample sizes. However, by casual examination of the values, it is striking how similar $2^{\text {nd }}$ generation extended and nuclear families are to each other and how different both are from the $1^{\text {st }}$ generation extended families. The average difference between the mean values for each of the dummy variables for the two types of extended families is 0.25 , compared with 0.05 if we make the same comparison between mean values for $2^{\text {nd }}$ generation extended vs. nuclear families. For the age of the household head the differences are 23.1 and 4.4, respectively. Among, the key differences are that first generation headed households have older heads, with less education, are more likely to have a female head, and the head is much less likely to work and to be the primary earner.

\section{Empirical Results}

To differentiate between the common preferences and Nash bargaining approaches to modeling household decision making we test whether a family member's social or economic status matter for the mobility decision. The mobility decision is a discrete variable indicating whether a household has moved over the last 5 years. For 


\section{Table 2 - Variable Means by Household Type}

\begin{tabular}{|c|c|c|c|c|}
\hline Variable & $\begin{array}{c}\text { Total - All } \\
\text { Households }\end{array}$ & $\begin{array}{c}1^{\text {st }} \text { Generation } \\
\text { Extended Family }\end{array}$ & $\begin{array}{c}2^{\text {nd }} \text { Generation } \\
\text { Extended }\end{array}$ & $\begin{array}{c}\begin{array}{c}\text { Nuclear } \\
\text { family }\end{array} \\
\end{array}$ \\
\hline \multicolumn{5}{|l|}{ Head Characteristics - Dummy Variables } \\
\hline Female Headed Household & 0.2814 & 0.4659 & 0.1761 & 0.2732 \\
\hline Family is Local Taiwanese & 0.7576 & 0.7337 & 0.7466 & 0.7599 \\
\hline Head is Above 60 Years Old & 0.1937 & 0.7069 & 0.0403 & 0.1637 \\
\hline Age of Head & 49.92 & 65.53 & 42.46 & 46.9 \\
\hline Head w/ High School Education & 0.2366 & 0.1184 & 0.2592 & 0.2442 \\
\hline Head w/ College Education & 0.3164 & 0.0953 & 0.4437 & 0.3261 \\
\hline \multicolumn{5}{|l|}{ HH Characteristics - Dummy Variables } \\
\hline Both Spouses Work & 0.2473 & 0.0999 & 0.3117 & 0.2548 \\
\hline HH Head is Primary Earner & 0.7208 & 0.2462 & 0.846 & 0.7493 \\
\hline HH Income from Eldest Generation in $\mathrm{HH}$ & 0.7858 & 0.2334 & 0.8558 & 0.823 \\
\hline No. of Earners & 1.538 & 1.664 & 1.67 & 1.522 \\
\hline HH With School Age Children & 0.4901 & 0.5028 & 0.4999 & 0.4887 \\
\hline No. of HH members & 3.885 & 4.683 & 4.395 & 3.798 \\
\hline \multicolumn{5}{|l|}{ Move Reason - Dummy Variables } \\
\hline Change in No. Of HH Members & 0.0671 & 0.0678 & 0.085 & 0.0661 \\
\hline Convenience For Job Or School & 0.1636 & 0.0954 & 0.1555 & 0.1691 \\
\hline Change For Better Neighborhood Amenities & 0.0728 & 0.0487 & 0.0845 & 0.0739 \\
\hline No. Of Observations & 175,421 & 11,527 & 8,137 & 155,757 \\
\hline
\end{tabular}


social status we differentiate between nuclear and extended families, and then whether for extended families the household head is in the eldest generation, where designation as head is assumed to indicate a higher social status for the household member so designated. Economic status is measured by whether a member contributes to household earnings. The explicit tests are as follows. First, if the added social status conferred by designating a member of the eldest generation as household head results in a lower conditional move probability, we interpret this as evidence in support of the bargaining model, where social status increases an individual's bargaining position. Second, if the conditional move probability falls when a member of that generation earns income, we interpret this as evidence in support of the bargaining model, where social status increases an individual's bargaining position. This effect would be intensified when the eldest generation household head is the primary earner. These probabilities are conditional on other variables presented in Table 2 such as household size, number of earners, age and education of head, and presence of school children. We choose to estimate the binomial mobility decision using a logit specification. The cumulative logistic distribution function has the following form:

$$
\Lambda(\gamma X)=\frac{e^{\gamma X}}{1+e^{\gamma X}}
$$

The empirical analysis follows below.

In Table 3 we present the basic mobility regression results. Regressions (1)-(3) are for the entire pooled sample, while regressions (4) and (5) are for extended family households only. Coefficient estimates for most of the control variables are quite stable across specifications and samples. Consistent with the literature, mobility declines with age and is lower in the presence of school age children. Here we find that Taiwan-born households are less likely to move, which likely reflects a stronger bond with a given neighborhood, and that mobility rises with education attainment. The 
Table 3 - Determinants of Mobility

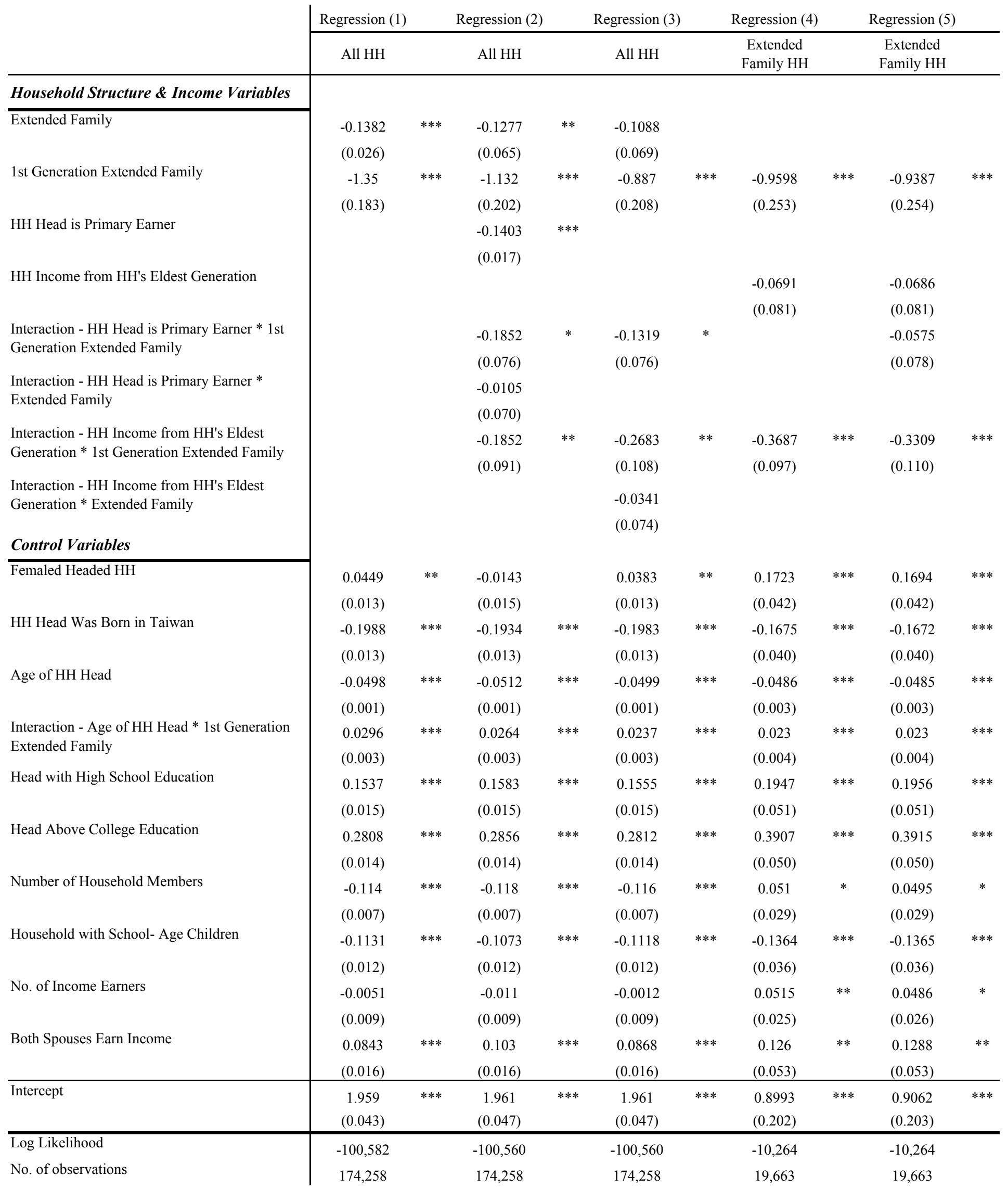

Significant level: $* * *:<0.01, * *:<0.05,{ }^{*}:<0.1$. Standard errors are in parenthesis. 
weakness of our data is that we observe neither income nor wealth, for individuals or households. The control variables are intended to be controls of themselves and to proxy for household permanent income. Our variables of interest will only suffer bias if there is a component of income and wealth correlated with them and uncorrelated with the included controls. We believe this to be unlikely.

We find robust results for the effects of family structure and social status of an elder generation on mobility. These results consistently reject the common preferences approach in favor of Nash bargaining treatment of decision making. The negative estimated coefficient on the extended family dummy in regressions (1)-(3) indicates lower mobility for extended families. This results controls for household size, number of earners, and the presence of school aged children, so the implication is clear that when a household includes an elder third generation, mobility declines for reasons other than household size, the need to optimize across multiple home-to-work trips and components of household income captured by these variables for the various earners. This mean effect is even lower for extended families where the household head is a member of the elder generation. However, the aggregate effect of the household having a first generation head depends on the age of the head, as the interaction between the first generation dummy and age reduces the marginal effect of age on mobility.

Having income increases an elderly household member's bargaining power. Regressions (2) and (3) include interaction terms to identify the marginal effect on conditional mobility when the eldest generation in an extended family has income. Not only is mobility explicitly lower when an elder head of household has income, this negative effect is even stronger when the elder is the primary earner. This latter distinction is only expected in the Nash bargaining framework, as how income is distributed among household members is of no matter in the common preferences model. When the elder generation has income in a second generation extended family 
(the interaction between the extended family and elder generation with income dummies in regression (3) combined with explicit interaction terms for first generation households), the marginal effect on conditional mobility is not statistically different from zero.

Regressions (4) and (5) sharpen the difference between first and second generation type extended households. These regressions are run only on the extended households. Mobility is lower for first generation type extended family households. Additionally, mobility is unchanged when an elder generation member in a $2^{\text {nd }}$ generation extended family household has income. For the $1^{\text {st }}$ generation extended household, mobility is explicitly lower when an elder generation member earns income. It is the presence of income that matters, rather than being the primary earner, as in regression (5) the estimated coefficient for the interaction between $1^{\text {st }}$ generation type and having the head as the primary earner is not statistically different from zero. Thus, it is only when the head is among the elder generation that earning income matters.

Interpreting marginal effects directly from the magnitudes in logit regressions is problematic. The estimated coefficients $\hat{\gamma}$ in (6) are not marginal probabilities as they would be in a linear regression. To calculate the same from a logit regression coefficient estimates requires the following transformation.

$$
\frac{\partial \Lambda(\gamma X)}{\partial X}=\Lambda(\gamma X)(1-\Lambda(\gamma X)) \gamma
$$

To make this analysis straight forward in Table 4 we present estimated cumulative probabilities calculated at both the population and extended family means. What stands out quite clearly is that the largest effect on probability is when the elder members in a first generation extended family earn income, with a marginal effect of minus 5 to 6 percentage points. This effect is less than one-fifth as large for $2^{\text {nd }}$ generation extended households. At the mean values, a $1^{\text {st }}$ generation extended household has a 4.5 


\section{Table 4 - Estimated Probabilities}

\begin{tabular}{|c|c|c|c|c|c|}
\hline & $\begin{array}{c}\text { Eldest } \\
\text { Generation } \\
\text { Earns Income }\end{array}$ & $\begin{array}{c}\text { Eldest } \\
\text { Generation is } \\
\text { Primary } \\
\text { Earner }\end{array}$ & $\begin{array}{c}\text { Population } \\
\text { Means }\end{array}$ & $\begin{array}{l}\text { Extended } \\
\text { Family } \\
\text { Means }\end{array}$ & $\begin{array}{c}\text { Extended } \\
\text { Family } \\
\text { Means }\end{array}$ \\
\hline Coeff. From Regression \# & & & (3) & $(4)$ & $(5)$ \\
\hline Family Type & & & & & \\
\hline Nuclear Family & Yes & Yes & $26.4 \%$ & & \\
\hline 2nd Gen. Extended Family & No & No & $24.3 \%$ & $18.5 \%$ & $18.5 \%$ \\
\hline 2nd Gen. Extended Family & Yes & No & $24.0 \%$ & $17.5 \%$ & $17.5 \%$ \\
\hline 1st Gen. Extended Family & No & No & $30.2 \%$ & $17.4 \%$ & $17.7 \%$ \\
\hline 1st Gen. Extended Family & Yes & No & $24.2 \%$ & $11.9 \%$ & $12.6 \%$ \\
\hline 1st Gen. Extended Family & Yes & Yes & $21.9 \%$ & & $12.0 \%$ \\
\hline \multicolumn{6}{|c|}{ Marginal Effects- Percentage Point Change } \\
\hline \multicolumn{6}{|c|}{ HH Head in Eldest Generation } \\
\hline 2nd vs 1 st Generation & & & & -1.11 & -0.81 \\
\hline Nuclear vs 1st Generation & & & -4.51 & & \\
\hline \multicolumn{6}{|c|}{ Eldest Generation Earns Income } \\
\hline 1st Generation $\mathrm{HH}$ & & & -5.97 & -5.42 & -5.09 \\
\hline 2nd Generation $\mathrm{HH}$ & & & -0.31 & -1.02 & -1.01 \\
\hline Eldest as Primary Earner & & & -2.34 & & -0.62 \\
\hline
\end{tabular}


percentage point lower marginal mobility probability than a nuclear family. The gap between the two types of extended families, when neither's elder generation earns income, is relatively small, about 1.0 percentage points. These estimated probabilities show quite clearly conditional effects of social status and economic power on family decision-making.

\section{Conclusion}

In this paper we study the mobility decisions of extended families. Our interest in this topic stems from the neglect of an analysis of how the social organization of households affects housing decisions in the mobility literature. In non-Western and traditional societies, extended families are more commonplace. Higher levels of immigration from Asia and Latin America are increasing the presence of these family structures in North American: immigrants are at least 50 percent more likely to live in extended family arrangements than are the native-born.

The results of our analysis indicate that mobility decisions vary by household social and economic organization. This holds both for the aggregate move probabilities and the marginal effects of selected measures of household characteristics. We find that as the social and economic importance of the oldest generation increases, the greater the marginal effects of those variables that measure disruption costs on household mobility. This suggests, as we expect, that the interests of a household member play a greater role in the mobility decision as their economic and social status in the household rises. 


\section{References}

BECKER, G. (1964) Human Capital, New York: Columbia University Press.

BOEHM, T. (1981) Tenure Choice and Expected Mobility: A Synthesis, Journal of

Urban Economics, 10, pp. 375-89.

BROWNING, M., BOURGUIGNON, F., CHAIPPORI, P.A., and LECHENE, V. (1994)

Income and Outcomes: A Structural Model of Intrahousehold Allocation, Journal of

Political Economy, 102 (6), pp. 1067-95.

CAI, J. (1989) Are Husbands and Wives Altruistically Linked? Evidence from the

MicroData. Boston University Working Paper.

CHANG, C.O. and CHEN, S.M. (1999) Households Life Cycle and Housing Demand

Decision Adjustment in Taipei, Taiwan, working paper presented at AREUEA/AsRES

International Conference, Maui, Hawaii.

CHIAPPORI, P.A. (1988a) Rational-Household Labor Supply, Econometrica, 56 (1), pp. 63-89.

(1988b) Nash-Bargained Household Decisions: A Comment,

International Economic Review, 29 (4), pp. 791-96. 
CLARK, W. A. V. and ONAKA J. L. (1983) Life Cycle and Housing Adjustment as Explanations of Residential Mobility, Urban Studies, 20, pp. 47-57.

DUNCAN, T. (1990) Intra-Household Resource Allocation: An Inferential Approach, Journal of Human Resources, 25 (4), pp. 635-64.

HAYASHI, F. (1995) Is the Japan Extended Family Altruistically Linked? A Test Based on Engel Curves, Journal of Political Economy, 103 (3), 661-74.

IOANNIDES, Y. M. (1987) Residential Mobility and Housing Tenure Choice Models, Regional Science and Urban Economics, 17, 265-87.

IOANNIDES, Y. M. and KAN, K. (1996) Structural Estimation of Residential Mobility and Housing Tenure Choice, Journal of Regional Science, 36 (3), pp. 335-63.

KAN, K. (1999) Expected and Unexpected Residential Mobility, Journal of Urban Economics, 45, pp. 72-96.

KAN, K. (2000) Dynamic Modeling of Housing Tenure Choice, Journal of Urban Economics, 48, pp. 46-49.

KENDIG, H. (1984) Housing Careers, Life Cycle and Residential Mobility: Implications for the Housing Market, Urban Studies, 21, pp. 271-283.

KIEL, K. (1994) The Impact of House Price Appreciation on Household Mobility, 
Journal of Housing Economics, 3 (2), pp. 98-108.

LIAO, T. (1994) Interpreting Probability Models: Logit, Probit, and Other Generalized Linear Models, Quantitative Applications in the Social Sciences, Sage University Paper Series 07-101, Sage: Thousand Oaks, CA.

MADDALA, G. (1983) Limited-Dependent and Qualitative Variables in Econometrics, Cambridge University Press, pp. 3-78.

MCELROY, M. and HORNEY, M.J. (1981) Nash-Bargained Household Decisions:

Toward a Generalization of the Theory of Demand, International Economic Review, 22 (2), pp. 333-50.

MCLEOD, P. and ELLIS, J. (1983) Alternative Approaches to the Family Life Cycle in the Analysis of Housing Consumption, Journal of Marriage and the Family, 45 (3), pp. 99-708.

MICHELSON, R. (1977) Environmental Choice, Human Behavior and Residential Satisfaction, Oxford: Oxford University Press.

MONTGOMERY, C. (1992) Explaining Home Improvement in the Context of Household Investment in Residential Housing, Journal of Urban Economics, 32, pp. 326-350. 
QUIGLEY, J. and WEINBERG, D. (1977) Intra-urban Residential Mobility: A Review and Synthesis, International Regional Science Review, 2 (1), pp. 41-66.

SCHULTZ, T.P., (1990) Testing the Neoclassical Model of Family Labor Supply and Fertility, Journal of Human Resources, 25 (4), pp. 599-634.

SEEK, N. (1983) Adjusting Housing Consumption: Improve or Move, Urban Studies, 20, pp. $455-469$.

ZORN, P. (1988) An Analysis of Household Mobility and Tenure Choice: An Empirical Study of Korea, Journal of Urban Economics, 24 (2), pp. 113-128. 


\section{ENDNOTES}

\footnotetext{
${ }^{1}$ These values are calculated from the 1990 US Census 1\% Public Use Micro Sample (PUMS) and the Statistics Canada 1996 Census Household Micro-Data sample. The variables provided in the Canadian household micro-data sample undercount extended families. To compensate we adjust our raw counts using the ratio (2.39) of the number of extended families in the US using the correct definition to the number obtained using the definition we must use for the Canadian data.

${ }^{2}$ (Chiappori, 1988a and 1988b) argues against the Nash model in favor of a Pareto-optimality approach that imposes fewer restrictions at the cost of less clear empirical implications.

${ }^{3}$ The social transactions or dislocation costs exist because of the transportation costs incurred in retaining existing contacts and the loss of utility and time costs as new contacts are formed after having moved. How these change with family size is not clear. Intra-family relationships can be expected to substitute for some external connections, but more family members will ensure more relationships to place that might be broken with a move.

${ }^{4}$ The utility from moving is the maximum utility available to the household at all other locations.
}

(Montgomery, 1992) incorporates improvements by comparing the maximum utility if the household moves to that if they stay, where staying is the maximum of no improvements versus improvements. As we note later, the housing stock in Taipei consists overwhelmingly of multi-storied, multi-family structures. This allows us to abstract away from the renovation and improvement decision in a way that is not possible for most owner-occupier households in North America.

${ }^{5}$ The job opportunities, quality of public schools, crime rate, and air pollution vary little across Taipei City. For instance, students are not required to attend neighborhood schools. There is a gap though between Taipei City and suburban areas because they fall under different government administration districts.

${ }^{6}$ We also exclude households who occupy units purchased from government housing projects, units that were inherited, or rental units. There are a total of 541,364 households. 44 percent of these are in our sample.

${ }^{7}$ A nuclear family is defined as a household with at most two generations living together, where all members are related by blood or marriage. $9.5 \%$ of these households have income from both two generations.

${ }^{8}$ Extended families are defined as those with at least three generations related by blood or marriage. 